\title{
POR QUE ENCAMINHAR AO ACOMPANHANTE TERAPÊUTICO? UMA DISCUSSÃO CONSIDERANDO A PERSPECTIVA DE PSICÓLOGOS E PSIQUIATRAS
}

\author{
Igor Londero* \\ Janaína Thais Barbosa Pacheco
}

\begin{abstract}
RESUMO. Esta pesquisa investigou quais os fatores que influenciam psiquiatras e psicólogos a indicarem o trabalho de Acompanhante Terapêutico (AT) e qual seu papel no tratamento de pacientes. Participaram do estudo três psicólogos e três psiquiatras, que trabalham em clínicas multiprofissionais de Porto Alegre. Foi utilizada uma entrevista semi-estruturada, constituída de sete questões abertas que abordaram os temas relativos ao problema de pesquisa. Os dados obtidos foram submetidos à análise de conteúdo qualitativa, que permitiu a delimitação das seguintes categorias: 1) Fatores para indicação de AT; 2) Papel no tratamento; 3) Habilidades e características necessárias para atuar como AT; 4) referencial teórico e área de conhecimento mais adequada para a prática. $\mathrm{O}$ trabalho do acompanhante terapêutico é percebido como coadjuvante no tratamento, exercendo um papel ativo e, muitas vezes, de crucial importância para o sucesso deste, por atuar diretamente no ambiente em que o paciente está inserido.
\end{abstract}

Palavras-chave: acompanhante terapêutico, profissionais de saúde mental, práticas terapêuticas.

\section{WHY LEADING PATIENTS TO BE ASSISTED BY A PSYCHOTHERAPIST? - A DISCUSSION CONSIDERING THE PERSPECTIVES OF PSYCHOLOGISTS AND PSYCHIATRISTS}

\begin{abstract}
This study has investigated the issues influencing psychiatrists and psychologists to lead patients to be assisted by a psychotherapist and its role on the treatment of patients, according to the perceptions of those professionals. Three psychiatrists and three psychologists of multi-professional clinics from Porto Alegre (RGS) were interviewed. A semistructured interview with seven open questions regarding this research subject was applied. The data obtained from the interviews were subjected to a qualitative analysis, resulting in the following categories subdivision: 1) Elements for psychotherapist indication; 2) The role of the psychotherapist during the treatment; 3) The necessary abilities and skills in relation to that profession; 4) Bibliographical reference and appropriate knowledge area for therapist practice. The Therapist work is recognized as co-adjuvant during treatment, exerting an active role and, sometimes, having a crucial role for the success of the treatment by acting within the patient's environment. Based on the participant's opinion, it was concluded that the most appropriate approach, regarding psychotherapy, was the cognitive-behavioral approach.
\end{abstract}

Key words: Psychotherapist, mental health professionals, therapist practice.

\section{¿POR QUÉ ENCAMINAR AL ACOMPAÑANTE TERAPÉUTICO? UNA DISCUSIÓN CONSIDERANDO LA PERSPECTIVA DE PSICÓLOGOS Y PSIQUIATRAS}

RESUMEN. Este trabajo investigó qué factores influencian psiquiatras y psicólogos a indicar el trabajo de Acompañante Terapéutico (AT), y cual es su papel en el tratamiento de pacientes, según la percepción de estos profesionales. Participaron en el estudio tres psicólogos y tres psiquiatras que trabajan en clínicas multiprofesionales de Porto Alegre (RS). Fue utilizada una entrevista semiestructurada, constituida de siete cuestiones de respuesta libre que abordaron los temas relativos al problema de investigación. Los datos obtenidos por medio de la entrevista fueron sometidos al análisis de contenido cualitativo, que permitió la delimitación de las siguientes categorías: 1) factores para indicación de acompañante terapéutico;

* Psicólogo, colaborador do PIETA - Programa Interdisciplinar de Estudos em Trauma e Ansiedade do CISAME - Centro Interdisciplinar de Saúde Mental de Porto Alegre.

\# Doutora em Psicologia do Desenvolvimento. Professora do curso de Psicologia da Universidade Luterana do Brasil - Campus Gravataí/RS. 
2) papel del acompañante terapéutico en el tratamiento; 3) habilidades y características necesarias para el acompañante terapéutico; 4) referencial teórico y área de conocimiento más adecuada para la práctica de acompañante terapéutico. El trabajo del acompañante terapéutico es visto como coadjuvante en el tratamiento, ejerciendo un papel activo y, muchas veces, de crucial importancia para el éxito de éste, por actuar directamente en el ambiente en el que el paciente está inserto. Se constató aún que el enfoque considerado más adecuado para el trabajo de AT sería, según los participantes, el cognitivocomportamental.

Palabras-clave: acompañante terapéutico, profesionales de salud mental, prácticas terapéuticas.

\section{HISTÓRIA DO ACOMPANHANTE TERAPÊUTICO}

O trabalho do acompanhante terapêutico (AT) surgiu na Argentina, no final da década de 1960, como uma necessidade clínica para pacientes cujas terapêuticas clássicas fracassavam. Inicialmente o AT foi chamado de "amigo qualificado", mas tal termo caiu em desuso pelo seu conteúdo amistoso e pouco profissional. O AT não é um amigo, ainda que possa estabelecer vínculos afetivos intensos com o paciente, mas sim, um agente terapêutico que realiza tarefas e é remunerado para isto (Mauer \& Resnizky, 1987; Porto \& Sereno, 1991).

Outros fatores foram decisivos para o trabalho do acompanhante terapêutico, como os movimentos antimanicomiais e a antipsiquiatria difundidos pela Europa entre as décadas de 1950 e 1960. É nesse momento e contexto que surgem na Inglaterra, Alemanha e EUA as chamadas "comunidades terapêuticas", cujo propósito era buscar novas formas de relação com a loucura, criando locais de acolhimento "concebidos como refúgio onde a verdade e o poder de contestação contidos no discurso louco poderiam ser reconhecidos" (Berger, Morettin \& Neto, 1991, p. 22).

No Brasil, no final da década de 1960, os ideais da antipsiquiatria começam a tomar corpo com o surgimento das primeiras comunidades terapêuticas no Rio de Janeiro, São Paulo e Porto Alegre. Nessas instituições, o recurso de acompanhamento terapêutico começa a ser utilizado e exercido por jovens, geralmente universitários. Esses "seriam capazes, sem ter que se preocupar com um futuro na carreira de enfermagem, de se permitir à aproximação e à experiência dos pacientes desintegrados" (Cooper, citado por Berger e cols., 1991, p. 23). Tais profissionais foram denominados de "auxiliares psiquiátricos" (Ibrahim, 1991).

O auxiliar psiquiátrico tinha como área de trabalho o sujeito dentro da própria instituição, e participava de todo o cotidiano dos pacientes, tanto de regime hospitalar-dia como de internação. Suas atividades consistiam em coordenar, junto aos outros profissionais, as atividades desenvolvidas, tais como jogos, realização de festas, atividades diárias, etc. Contudo, na década de 1970, com a política do regime militar de privilegiar a internação asilar em detrimento de outros tipos de tratamento da loucura, ocorre o declínio das comunidades terapêuticas, fazendo com que os auxiliares psiquiátricos percam sua funcionalidade e sua área de trabalho, pois remunerálos tornara-se inviável para tais instituições. Assim, os auxiliares psiquiátricos que trabalhavam nas instituições continuaram a ser solicitados para trabalhos particulares na residência dos pacientes e os acompanhamentos passaram a ser feitos no ambiente doméstico, proporcionando entrar em contato direto com o cotidiano e o universo familiar (Ibrahim, 1991).

O acompanhante terapêutico exercia funções tais como administrar medicações, ser confidente, egoauxiliar, e até mesmo, fazer o papel de superego (Ibrahim, 1991). Esta forma de intervenção, baseada nos pressupostos psicanalíticos, definiu sua área de atuação principalmente com pacientes psicóticos, numa busca por reintegrá-los na sociedade e no vínculo familiar (Ibrahim, 1991; Mauer \& Resnizky, 1987; Porto \& Sereno, 1991; Zamignani \& Wielenska, 1999).

Mauer \& Resnizky (1987) sugerem as funções principais do acompanhante terapêutico, sendo elas: 1) conter o paciente; 2) oferecer-se como modelo de identificação; 3) trabalhar em um nível dramáticovivencial e não interpretativo; 4) emprestar o "ego"; 5) perceber, reforçar e desenvolver a capacidade criativa do paciente; 6) informar sobre o mundo objetivo do paciente; 7) representar o terapeuta; 8) atuar como agente ressocializador; e 9) servir como catalisador das relações familiares.

Esses autores ressaltam ainda as condições que um indivíduo deve ter para ser um acompanhante terapêutico. Entre essas condições inclui-se vocação para a assistência, alto grau de comprometimento, interesse por trabalhar em equipe, maturidade, autonomia, capacidade de empatia e vínculo, flexibilidade em estabelecer limites fortes, capacidade de aliar a teoria com a prática, além de ausência de 
preconceitos e estereótipos (Mauer \& Resnizky, 1987).

Analisando o contexto histórico em que o AT foi criado, percebemos que sua base teórica fundamental tem sido a psicanalítica, principalmente naquilo que se refere à etiologia das patologias, em especial, daquelas vinculadas às psicoses. Dentro de uma proposta psicanalítica mais atual destacamos o trabalho de Ribeiro (2002), que propõe uma perspectiva lacaniana no campo das psicoses e das neuroses graves, onde se insere a atuação do AT como forma de "limitar a desorganização do imaginário e servir como pontos de ancoragem na "realidade"" (p. 85), atuando de maneira a reatar o laço social a partir da restauração da ordem simbólica. Sendo assim, "o dispositivo do acompanhamento dirige-se à mediação das relações do psicótico com o mundo, na rearticulação dos vínculos sociais e na reconstrução da imagem corporal” (p. 83).

\section{ACOMPANHANTE TERAPÊUTICO E TERAPIA COMPORTAMENTAL}

Nas décadas de 1960 e 1970, com a difusão dos pressupostos da Análise do Comportamento e sua aplicabilidade no contexto clínico, surgem os "modificadores de comportamento", que utilizavam técnicas comportamentais em programas terapêuticos (Barcellos \& Haydu, 1998; Zamignani \& Wielenska, 1999). Três aspectos marcaram esta proposta: 1) parecia viável a transposição do modelo de laboratório para a situação clínica; 2) pretendia-se atender à comunidade científica com o rigor da produção de conhecimento; e 3) pretendia-se atender aos clientes promovendo melhoras significativas (Guedes, 1993).

O processo terapêutico desenvolvido nessa época limitava-se à aplicação de procedimentos para diminuir a freqüência de comportamentos considerados problemáticos e/ou aumentar a frequiência de respostas desejadas. Essa prática gerou críticas ao modelo teórico e à sua transposição do modelo experimental com animais para aplicação em humanos num contexto clínico (Baptistussi, 2001). No começo, considerava-se que a Terapia Comportamental era limitada e que se empregaria principalmente no tratamento de fobias específicas ou problemas localizados, enfocando os comportamentos neuróticos e a utilização de técnicas que procuram reduzir a ansiedade dos pacientes (Barcellos \& Haydu, 1998; Caballo, 1999; Range, 1998).

Em contrapondo a estas críticas, a Terapia Comportamental contemporânea reflete uma combinação de procedimentos verbais e de métodos multidimensionais em vez de abordagens únicas.
Direciona maior atenção às responsabilidades do terapeuta e do cliente e à busca de ir além dos limites restritos do condicionamento tradicional com um enfoque na solução de problemas, o que levou muitos analistas comportamentais a dedicar-se principalmente ao trabalho de consultório (Guedes, 1993; Range, 1998).

Neste sentido, surge a ênfase no uso da análise funcional, que é, segundo Matos (1999), a busca por identificar o valor de sobrevivência de determinado comportamento em relação ao ambiente, ou seja, levar em conta aspectos do ambiente e a função que o comportamento tem neste.

No início da década de 1990, a Terapia Comportamental começa a se destacar na comunidade psiquiátrica pelos resultados obtidos com o uso de técnicas comportamentais em transtornos psiquiátricos severos. Tais intervenções caracterizam-se por um "trabalho intensivo, de cunho multiprofissional, realizado em instituições e ou no ambiente natural do cliente" (Zamignani \& Wielenska, 1999, p. 158).

Zamignani e Wielenska (1999) referem que atualmente no Brasil o trabalho em situação natural tem sido feito, na maioria das vezes, por estudantes e/ou profissionais recém-formados, como é o caso do acompanhante terapêutico. Tal fato se deve, segundo estes autores, ao alto custo que esta tarefa pode representar para a família, e em se tratando de um estudante ou recém-formado, geralmente as expectativas de remuneração são menores.

Algumas habilidades são pré-requisitos para o aluno que se propõe a trabalhar como AT em abordagem comportamental, e dentre elas estão: a) treinamento em observação; b) conhecer conceitos básicos de análise do comportamento; c) conhecimento de técnicas de entrevista; d) capacidade de estabelecer relação terapêutica; e) ter clareza na aplicação das técnicas; f) ter noções básicas de psicopatologia e psicofarmacoterapia (Zamignani \& Wielenska, 1999).

\section{MÉTODO}

\section{Delineamento}

Trata-se de uma pesquisa qualitativa de cunho exploratório, junto a profissionais da área de saúde mental, com a finalidade de investigar a percepção acerca da atuação do AT na prática clínica.

\section{Participantes}

A amostra da presente pesquisa foi selecionada intencionalmente. Participaram seis profissionais homens e mulheres -, sendo três psicólogos e três 
psiquiatras da cidade de Porto Alegre. Para compor a amostra os participantes deveriam atender aos seguintes critérios: atuar como psicoterapeuta há mais de dois anos, trabalhar em equipe multi ou interdisciplinar e ter experiência em atendimento de pacientes em conjunto com um acompanhante terapêutico. O Quadro 1 apresenta detalhadamente as características da amostra.

\begin{tabular}{|c|c|c|c|c|c|c|}
\hline & P1 & $\mathbf{P 2}$ & P3 & P4 & P5 & P6 \\
\hline Profissão & Psicólogo & Psiquiatra & Psiquiatra & Psicólogo & Psiquiatra & Psicólogo \\
\hline $\begin{array}{l}\text { Formação } \\
\text { específica }\end{array}$ & $\begin{array}{l}\text { Especialização em } \\
\text { infância e } \\
\text { adolescência }\end{array}$ & $\begin{array}{l}\text { Residência em } \\
\text { psiquiatria }\end{array}$ & $\begin{array}{l}\text { Residência em } \\
\text { psiquiatria }\end{array}$ & $\begin{array}{l}\text { Pós-graduanda em } \\
\text { psic. Clinica }\end{array}$ & \begin{tabular}{|c|} 
Residência em \\
psiquiatria e pós- \\
graduando em terapia \\
cognitiva
\end{tabular} & $\begin{array}{l}\text { Especialização em } \\
\text { Terapia racional- } \\
\text { emotiva }\end{array}$ \\
\hline $\begin{array}{c}\text { Tempo de atuação } \\
\text { na área }\end{array}$ & Mais de 8 anos & Mais de 8 anos & Mais de 8 anos & Mais de 2 anos & Mais de 8 anos & Mais de 8 anos \\
\hline $\begin{array}{c}\text { Método de trabalho } \\
\text { da equipe }\end{array}$ & Interdisciplinar & Interdisciplinar & $\begin{array}{l}\text { Interdisciplinar e } \\
\text { multidisciplinar }\end{array}$ & Interdisciplinar & Multidisciplinar & Interdisciplinar \\
\hline $\begin{array}{c}\text { Características dos } \\
\text { pacientes que } \\
\text { atende }\end{array}$ & $\begin{array}{c}\text { Crianças, } \\
\text { adolescentes e adultos }\end{array}$ & Adultos e idosos & Adultos & $\begin{array}{l}\text { Adolescentes e } \\
\text { adultos }\end{array}$ & $\begin{array}{c}\text { Crianças, } \\
\text { adolescentes e } \\
\text { adultos } \\
\end{array}$ & $\begin{array}{c}\text { Crianças, } \\
\text { adolescentes e adultos }\end{array}$ \\
\hline $\begin{array}{l}\text { Referencial teórico } \\
\text { referido }\end{array}$ & \begin{tabular}{|c|} 
Compreensão \\
analítica, e por vezes, \\
abordagem cognitivo- \\
comportamental
\end{tabular} & $\begin{array}{c}\text { Biológico e } \\
\text { psicodinâmico }\end{array}$ & $\begin{array}{c}\text { Biológico e } \\
\text { psicodinâmico }\end{array}$ & Psicanalítico & $\begin{array}{l}\text { Biológico e } \\
\text { cognitivismo }\end{array}$ & $\begin{array}{l}\text { Cognitivo- } \\
\text { comportamental }\end{array}$ \\
\hline
\end{tabular}

Quadro 1. Descrição dos participantes da pesquisa

\section{Instrumentos e materiais}

Os dados foram coletados através de uma entrevista semi-estruturada constituída de um total de sete questões abertas. A entrevista foi construída considerando os objetivos do estudo e a revisão da literatura. Os temas abordados na entrevista foram os seguintes: 1) critérios para indicação ao AT, 2) papel do AT na equipe, 3) características e habilidades esperadas do AT, 4) referencial teórico adequado para o AT e 5) formação mais adequada para o AT. As entrevistas foram realizadas individualmente $\mathrm{e}$ gravadas em fitas cassete, sendo posteriormente transcritas. Os participantes autorizaram sua participação na pesquisa assinando o Termo de Consentimento Livre e Esclarecido.

\section{Procedimentos de coleta de dados}

Os participantes foram selecionados em clínicas de Porto Alegre em que reconhecidamente há a atuação de acompanhantes terapêuticos. Após a apresentação do projeto e a autorização para a realização da coleta de dados, as entrevistas foram agendadas por telefone, sendo realizadas no próprio ambiente de trabalho dos participantes.

\section{Análise dos dados}

Os dados coletados a partir das entrevistas sofreram análise de conteúdo qualitativa (Bardin, 1977; Laville \& Dionne, 1999). Considerando-se a natureza do estudo, as categorias foram determinadas a partir da leitura dos dados coletados (modelo aberto) e tiveram o objetivo de responder aos problemas de pesquisa apresentados anteriormente.

\section{APRESENTAÇÃO E DISCUSSÃO DOS RESULTADOS}

A análise de conteúdo (Bardin, 1977) possibilitou a construção das seguintes categorias:

1. Fatores para indicação de acompanhante terapêutico;

2. Papel do acompanhante terapêutico no tratamento;

3. Habilidades e características necessárias para o acompanhante terapêutico;

4. Referencial teórico e área de conhecimento mais adequada para a prática de acompanhante terapêutico.

A seguir são apresentadas as categorias e suas respectivas descrições, bem como a caracterização de cada tema. A fim de melhor organizar os dados, a discussão será realizada por categoria.

\section{Categoria 1 - Fatores para indicação de acompanhante terapêutico}

Nesta categoria foram incluídas as falas dos participantes que referem quais os fatores são considerados pelos profissionais no encaminhamento do paciente para acompanhante terapêutico. A categoria 1 foi dividida em sete subcategorias, sendo 
elas: incapacidade funcional, dificuldades da família, classes diagnósticas, internação psiquiátrica, adesão ao tratamento, déficit no comportamento social e limites da psicoterapia.

Inicialmente, observa-se que as indicações para acompanhante terapêutico (AT) são influenciadas pelas "incapacidades funcionais" que o paciente apresente. Nestas, estão incluídas as habilidades mais básicas, tais como cuidados com a higiene, autogerenciamento, autocontrole, etc, que são chamadas de atividades da vida diária (AVD’s). A dificuldade na execução das atividades diárias pode estar presente em diversos quadros psicopatológicos, tanto na vida adulta como na infantil (Amiralian, Pinto, Ghirardi, Masini \& Pasqualin, 2000).

Segundo Pinto e cols. (2002), incapacidade funcional é a presença de dificuldade ou a impossibilidade de desempenhar atividades da vida cotidiana. Assim o termo "incapacidade" representa uma restrição da habilidade para desempenhar uma atividade considerada normal para o ser humano, e surge como consequiência direta ou é resposta do indivíduo a uma deficiência psicológica, física ou sensorial. Representa a objetivação da deficiência e reflete os distúrbios da própria pessoa, nas atividades e comportamentos essenciais à vida diária (Amiralian e cols., 2000).

Espera-se de um AT que ele realize atividades com o paciente e que lhe proporcione uma melhora de seu quadro, seja no ambiente social seja em sua casa. As intervenções devem ser direcionadas para os problemas específicos que o paciente apresenta, tais como as relacionadas às incapacidades funcionais, buscando-se a autonomia e autogerenciamento de sua vida.

Uma ferramenta bastante útil na investigação das incapacidades apresentadas pelo indivíduo é o questionário de atividades da vida diária (QAVD), no qual podem ser observadas as áreas de maior comprometimento a fim de proporcionar o melhor planejamento das intervenções e obter, assim, um maior sucesso (Amiralian e cols., 2000).

Não obstante, constata-se que as "dificuldades da família" constituem um fator para o encaminhamento para AT, principalmente naquelas famílias nas quais estão presentes características como falta de disponibilidade, vínculos atribulados e falta de paciência. Desta forma, os familiares podem experienciar o estresse, conforme observam Lee e Gotlib (citados por Brito \& Dessen, 1999), como resultado da frustração e sobrecarga nas atividades diárias. Nestes casos, o AT serviria como uma alternativa para realizar atividades relacionadas à atenção e ao cuidado do paciente, que a família não consegue desempenhar por percebê-las como incômodas ou onerosas.

No que se refere à subcategoria "classes diagnósticas", observa-se a referência àqueles quadros em que as incapacidades funcionais são mais frequientes, tais como casos de transtornos de desenvolvimento, psicoses e doenças degenerativas. Outro aspecto abordado pelos participantes, embora não com tanta freqüência, são aqueles casos em que também há um leve comprometimento funcional. Nestes incluem-se os transtornos de ansiedade e de dependência de substâncias psicoativas, nos quais pode estar presente a perda de autonomia e de autocontrole.

Observa-se que, na percepção dos participantes, o AT desempenha um trabalho que muito nos lembra os primórdios da Terapia Comportamental (décadas de 1960 e 1970), principalmente no que se refere à intervenção em problemas específicos, como os casos de fobia.

$\mathrm{Na}$ subcategoria "internação psiquiátrica" observou-se que os profissionais consideram indicada a intervenção do AT tanto para os pacientes cuja internação psiquiátrica tenha sido prolongada, pelas características da psicopatologia ou das condições socioeconômicas da família, quanto para aqueles que não têm condições de internação, por motivos financeiros ou familiares. Entre estes últimos estão os pacientes que apresentem risco iminente de suicídio, e os que, por indicação dos participantes, podem ser monitorados pelo AT em seu próprio ambiente doméstico.

$\mathrm{Na}$ subcategoria "adesão ao tratamento" são referidos os casos daqueles pacientes que têm dificuldades em manter o que foi prescrito ou combinado. Assim, a indicação para o AT, na percepção dos participantes da pesquisa, estaria ligada à busca do cumprimento das combinações feitas entre terapeuta e paciente, incluindo a prescrição de medicação e o desenvolvimento de condutas mais adequadas.

No que se refere ao "déficit no comportamento social" como fator para indicação para AT, constata-se que o encaminhamento é dirigido àqueles pacientes que têm um comprometimento na capacidade de relacionamento social dentro de sua comunidade, devido a seu quadro sindrômico ou às limitações que este impõe. Neste sentido, podemos utilizar a definição de "desvantagem", que seria, segundo Amiralian e cols. (2000), um prejuízo para o indivíduo, resultante de uma deficiência ou uma incapacidade que o limita ou o impede no desempenho 
de papéis esperados para a idade, sexo e cultura. Neste caso, torna-se importante a distinção dos termos "incapacidade" e "desvantagem". O primeiro está diretamente relacionado às funções mais básicas do indivíduo, enquanto o segundo refere-se aos prejuízos que a primeira pode impor, como é o caso do desempenho social, por exemplo. (Amiralian e cols., 2000).

Quanto aos "Limites da psicoterapia”, observa-se que esta subcategoria aponta o trabalho do AT como uma alternativa que vem a suprir a necessidade de complementação do tratamento psicoterápico, principalmente em casos em que as intervenções devem ser estendidas para fora do consultório. Nesse sentido, a intervenção no ambiente natural do cliente propicia condições para a abordagem imediata do comportamento. Assim, o AT poderá intervir diretamente nas respostas e nas conseqüências do comportamento do sujeito (Baumgarth, Guerrelhas, Mazer \& Zamignani, 1999), tornando sua atuação mais eficaz na modificação e na aprendizagem de padrões comportamentais.

Segundo Baumgarth e cols. (1999), a variável fundamental que define a decisão de intervenção no ambiente natural é o repertório comportamental do cliente, pois muitas vezes "é no ambiente natural que encontramos dispostos os reforçadores necessários para a aprendizagem de novas habilidades, a partir da exposição direta à contingência e teste efetivo de hipóteses" (p. 167). Assim, o AT vem a atuar junto ao paciente em seu ambiente, adequando reforçadores e analisando as contingências advindas destes.

\section{Categoria 2 - Papel do acompanhante terapêutico no tratamento}

Nesta categoria foram incluídas as falas dos participantes que referem o papel do acompanhante terapêutico no tratamento de pacientes com transtorno psiquiátrico. A categoria 2 foi dividida em quatro subcategorias, que são: complementar da terapia, auxiliar a família, atuar fora do consultório e de muita importância.

$\mathrm{Na}$ subcategoria "complementar da terapia" observa-se que o AT é percebido pelos profissionais participantes como um co-terapeuta, influenciando o terapeuta principal em suas decisões e participando desde a elaboração do planejamento terapêutico até mudanças de conduta frente a determinado paciente. Quando ocorre a intervenção do AT no ambiente natural do cliente, a troca de informações entre os profissionais é de crucial importância. Essa troca pode ser realizada na supervisão ou em reunião, onde são discutidos assuntos relevantes e decididas as ações terapêuticas (Baumgarth e cols., 1999). Nota-se também que o AT proporciona informações importantes ao terapeuta principal, pois oferece outro olhar sobre o paciente, principalmente por estar em um ambiente privilegiado de observação (Zamignani \& Wielenska, 1999).

Quanto à troca de informações sobre o paciente e à influência do AT no tratamento desse, é importante salientar que, necessariamente, a equipe deverá ser coesa o bastante e crítica 0 suficiente para poder rever estratégias e conceitos, pois é comum na prática clínica que haja entre os profissionais movimentos contrários, que dificultam a interação e a troca de informações. Assim, é imperativo que os papéis dentro da equipe facilitem a comunicação, diminuindo ao máximo as posições hierárquicas de superioridade, que podem inibir qualquer tipo de troca autêntica de informações.

$\mathrm{Na}$ subcategoria "auxiliar a família" observa-se que, para os participantes, o papel do AT junto à família diz respeito a orientá-la no sentido de facilitar o convívio entre os membros, buscando a reorganização de papéis e a aquisição de novos repertórios. Nesse caso, o AT pode servir até mesmo como modelo de identificação no que diz respeito ao manejo do paciente, demonstrando condutas mais adequadas que facilitem a melhora de seu quadro.

Quanto ao seu papel de "atuar fora do consultório", observa-se que os profissionais percebem as atividades do AT intimamente ligadas ao espaço físico no qual essas ocorrem, ou seja, seu trabalho está fundamentado em situações extraconsultório e no ambiente natural do cliente. A atuação do AT tem como foco de trabalho as situações cotidianas que o paciente enfrenta, tais como ir ao banco, à faculdade, a festas, a viagens, etc; fazendo o trabalho de monitoração (risco de uso ou abuso de substâncias), de controle (casos de agressividade) e de intervenção in loco. Assim, "é tarefa do AT desenvolver as atividades terapêuticas e procedimentos planejados, seja em situação natural, no consultório ou na instituição, sempre sob supervisão constante" (Zamignani \& Wielenska, 1999, p. 159).

Sobre sua área de trabalho, é importante que o AT não tenha nenhuma restrição quanto a locais ou situações que possam desagradá-lo, como é o caso, por exemplo, de um paciente que goste de frequientar festas "Rave" tendo um AT que se negue a enfrentar filas e grandes concentrações de pessoas. Neste caso, o AT deverá ter desenvoltura e disponibilidade para realizar tarefas que não sejam de seu agrado, tendo-se em vista que, seja qual for a situação em que é requisitado, esta deverá ser percebida como oportunidade de intervenção terapêutica. 
Na subcategoria "de muita importância", observase que o trabalho de AT é percebido pelos profissionais como fundamental, e em alguns casos, torna-se o pilar central de todo planejamento terapêutico, pelo fato de passar mais tempo com o paciente e ter uma visão privilegiada da vida cotidiana deste.

\section{Categoria 3 - Habilidades e características necessárias para o trabalho de acompanhante terapêutico}

Nesta categoria foram incluídas as falas dos participantes que descrevem as características e habilidades necessárias para o trabalho de AT. A categoria 3 foi dividida em seis subcategorias, a saber: características e habilidades pessoais, características de idade e gênero, possuir experiência de AT, características físicas, conhecimentos teóricos, características definidas pelo perfil do paciente.

$\mathrm{Na}$ subcategoria "características e habilidades pessoais", observa-se que a principal característica esperada pelos profissionais de um AT é sua adequação relacionada ao ambiente em que atua, já que ele entra na intimidade do paciente e de sua família. Nestes casos, o AT deve estar ciente de que é um profissional e está trabalhando, não devendo ter intimidade e manter o máximo de discrição. Por sua vez, também deve ter adequação quanto ao tipo de trabalho que exerce, devendo observar que cuidados básicos como uso de roupas e calçados adequados são de extrema importância, por se tratar de um trabalho onde o imprevisto é sempre esperado. Outras características também são citadas, tais como paciência (pacientes idosos), perspicácia (pacientes dependentes químicos), dinamismo em propor atividades e firmeza nas atitudes (nos casos de pacientes muito "sedutores").

Quanto à subcategoria "características de idade e gênero", observa-se que os profissionais buscam acompanhantes terapêuticos com características de acordo com as do paciente, tais como sexo e idade, principalmente pelo fato de que estas podem facilitar a relação entre ambos, evitando que o AT seja percebido pelo paciente como um "vigilante" ou algo do gênero.

$\mathrm{Na}$ subcategoria "possuir experiência como AT" observa-se que os profissionais têm preferência por ATs já experientes e que saibam lidar com situações imprevistas, fato este percebido como fundamental para que haja tranqüilidade no encaminhamento. Na prática, observa-se que podem ocorrer diversas situações imprevisíveis, tais como pacientes que se tornam agressivos durante o acompanhamento em um shopping, ou então, um paciente dependente químico que se utiliza de pequenos descuidos do AT para fazer uso de drogas.

No que se refere à subcategoria "características físicas", observa-se que, para alguns profissionais participantes, principalmente aqueles cujos pacientes apresentam quadros mais severos ,como é o caso de psiquiatras, o AT deve ter um bom condicionamento físico que lhe proporcione agilidade em lidar com situações de risco, tanto para si como para o paciente. Naqueles casos onde há risco de agressão, fuga, autolesão e suicídio, o AT deve ter agilidade que lhe garanta uma rápida resposta e ser fisicamente capaz de ao menos executar uma contenção mecânica, se necessário.

Já no caso de "conhecimentos teóricos" necessários para exercer o trabalho de AT, observa-se que tanto os psicólogos quanto os psiquiatras entrevistados esperam um conhecimento clínico básico, especificamente naquilo que se refere à descrição de sinais e sintomas. Esse conhecimento é percebido como diferencial no que tange à representação de um trabalho mais técnico, e não somente "intuitivo".

Finalmente, na subcategoria "características definidas pelo perfil do paciente", percebe-se que o profissional busca fazer uma observação mais acurada do contexto do paciente, para então definir as habilidades esperadas do AT. Dessa forma, em geral, as características do AT buscadas pelos profissionais estão diretamente ligadas a aspectos diagnósticos, sociais e psicológicos daquele paciente específico que será encaminhado.

Categoria 4 - Referencial teórico e área de conhecimento mais adequados para a prática de acompanhante terapêutico

Nessa categoria foram incluídas as falas dos participantes que referem qual o referencial teórico e qual a área de conhecimento considerados mais adequados para a prática de AT. A categoria 4 foi dividida em três subcategorias, quais sejam: referencial teórico, profissionais da área da saúde em geral e psicólogos ou estudantes de psicologia.

O "referencial teórico" percebido como o mais adequado para o trabalho de Acompanhante Terapêutico, segundo os profissionais que participaram da pesquisa, é o cognitivo-comportamental. Neste sentido, observa-se que alguns profissionais, ao citarem esta abordagem, estão, na verdade, referindo-se ao uso de técnicas de modificação do comportamento. Observa-se, ainda, que os profissionais entrevistados que seguem uma orientação psicanalítica destacam, no trabalho do AT, o uso de técnicas comportamentais acrescidas da 
compreensão psicodinâmica, demonstrando uma tentativa de combinar as duas abordagens.

Sobre o emprego de técnicas cognitivo-comportamentais no contexto clínico, Banaco (1999) refere que o uso do instrumental desta abordagem está ligado aos resultados que se têm obtido nas diversas patologias. No entanto, o sucesso empírico de tais técnicas tem gerado uma tendência à sua utilização de forma indiscriminada por parte dos profissionais, sem o mínimo de fundamentação teórica. Sobre isto, esse mesmo autor utiliza-se de uma metáfora que pode ilustrar essa postura: "Quando a ferramenta que temos na mão é um martelo, tudo à nossa frente vira prego" (Banaco, 1999, p. 75).

A crítica derivada da metáfora representa, e muito bem, o estado atual da abordagem cognitivocomportamental e como ela tem sido aplicada e referida por alguns profissionais. Muitas vezes essa abordagem é reduzida ao emprego de técnicas para problemas específicos, sem, contudo, observar o momento e o contexto em que a técnica deve ser empregada. Como forma mais adequada e eficaz para o emprego da técnica, é imprescindível que o terapeuta tenha habilidade para realizar uma análise funcional, levando em conta aspectos do ambiente (incluindo história de vida) e a função que o comportamento tem nesse ambiente (Matos, 1999).

Quanto à subcategoria "profissionais da saúde em geral", os participantes referem que o trabalho de acompanhante terapêutico pode ser executado por profissionais de diversas áreas, não necessariamente daquelas chamadas "psi". Observa-se, neste sentido, uma referência especial à Terapia Ocupacional e à Enfermagem, que são percebidas como parcialmente instrumentalizadas para a atuação fora da instituição e/ou do consultório.

\section{CONSIDERAÇÕES FINAIS}

O objetivo da presente pesquisa foi investigar quais os fatores que influenciam psiquiatras e psicólogos na decisão para o encaminhamento para acompanhamento terapêutico. Além disso, buscou-se verificar como esses profissionais percebem o papel do AT no tratamento dos pacientes. A partir dos dados coletados, constatou-se que os profissionais encaminham para acompanhamento terapêutico aqueles pacientes cujas características refletem uma situação de incapacidade e/ou desvantagem, principalmente quando essas provêm de quadros psicopatológicos graves. Não obstante, observa-se que o encaminhamento para AT está diretamente ligado ao julgamento subjetivo do profissional que avalia o caso, levando em consideração aspectos familiares, diagnósticos, limites da psicoterapia e a história do paciente.

O papel do acompanhante terapêutico no tratamento dos pacientes é percebido pelos profissionais como de muita importância, principalmente nos casos em que se exige atenção e intervenções fora do ambiente de consultório. É esperado que o AT venha a ser um agente complementar na melhora do paciente e que contribua para a qualidade de vida, tanto do paciente como de sua família.

$\mathrm{Na}$ análise dos dados observaram-se algumas divergências significativas entre os profissionais, principalmente nos temas encontrados na categoria 4 (referencial teórico e área de conhecimento mais adequada para a prática de AT). Nessa categoria, os participantes demonstraram diferentes opiniões quanto à área de conhecimento que seria mais adequada para o trabalho de AT, no que refere à formação e instrumentalização acadêmica. De certa maneira esta divergência já era esperada, tendo-se em vista que a profissão de acompanhante terapêutico inexiste como especialização ou aprimoramento profissional, não se constituindo, ainda, em uma prática "legal", tampouco em atividade reconhecida como privativa de alguma área de conhecimento e profissão.

Outra divergência em relação à mesma categoria diz respeito a questões de cunho teórico, mais precisamente à abordagem teórica vista pelos profissionais como a mais adequada para a prática de AT (categoria 4). Sobre este tema, pôde-se constatar que a maioria dos profissionais entrevistados refere a abordagem cognitivo-comportamental como a mais adequada, mesmo tendo referido, em alguns casos, utilizar-se de outro referencial em sua prática diária (ver características da amostra - Quadro 1).

Tendo em vista a incompatibilidade teórica encontrada, podemos supor que a terapia cognitivocomportamental na prática do AT é vista em um contexto apenas de aplicação das técnicas de modificação de comportamento, e não como um conjunto de conceitos e de possibilidades de intervenção que constituem uma abordagem terapêutica mais ampla.

Como em qualquer pesquisa, podem ser encontradas neste trabalho algumas limitações. A principal dificuldade metodológica encontrada refere-se à composição da amostra. Isso porque os critérios estabelecidos para a seleção dos participantes reduziram consideravelmente o número de profissionais que poderiam ser entrevistados. Dessa forma, a possibilidade de generalização dos resultados encontrados fica restrita, sugerindo-se a realização de outras investigações com amostras maiores e mais diversificadas. 
Como foi salientado no texto, o trabalho de AT pode ser considerado bastante recente e ainda em fase de consolidação tanto teórica quanto técnica. Tal característica reflete-se na bibliografia disponível sobre o tema. Dessa forma, outra limitação encontrada foi a escassez de publicações atualizadas sobre a atuação do AT. Entende-se que este estudo, de cunho exploratório, pode contribuir para a compreensão e a delimitação dessa área de conhecimento e para a elaboração de novos projetos de pesquisa e conseqüentes publicações.

A investigação sobre a atuação do AT, sob a perspectiva dos profissionais, psicólogos e psiquiatras, pareceu importante, tendo-se em vista que estes são a principal fonte de encaminhamentos.

Apesar de os resultados indicarem divergências quanto à formação do AT, espera-se salientar a urgência de constituição de cursos de capacitação direcionados para profissionais da saúde em geral, proporcionando melhor qualidade técnica no tratamento dos pacientes e conduzindo essa profissão para o caminho de sua regulamentação.

\section{REFERÊNCIAS}

Amiralian, M., Pinto, E., B., Ghirardi, M., Masini, E. \& Pasqualin L. (2000). Conceituando deficiência. Revista de Saúde Pública, 34(1), 97-103.

Banaco, R. A. (1999). Técnicas cognitivo-comportamentais e análise funcional. Em R. R. Kerbauy (Org.), Sobre comportamento e cognição: psicologia comportamental e cognitiva - da reflexão teórica à diversidade de aplicação (Vol. 4, pp. 75-82). Santo André: Esetec.

Baptistussi, M. C. (2001). Bases teóricas para o bom atendimento em clínica comportamental. Em R. C. Wielenska (Org.), Sobre comportamento e cognição: questionando a teoria e as intervenções clínicas e em outros contextos. (Vol. 6, pp. 150156). Santo André: Esetec.

Barcellos, A. B. \& Haydu, V. B. (1998). História da psicoterapia comportamental. Em B. Rangé (Org.), Psicoterapia comportamental e cognitiva: pesquisa, prática, aplicações e problemas. (pp. 16-34). Campinas: Editorial Psy.

Bardin, L. (1977). Análise de conteúdo. Lisboa: Edições 70.

Baumgarth, G. C., Guerrelhas, F. F., Kovac, R., Mazer, M. \& Zamignani, D. R. (1999). A intervenção em equipe de terapeutas no ambiente natural do cliente e a interação com outros profissionais. Em R. R. Kerbauy \& R. C. Wielenska (Orgs.), Sobre comportamento e cognição: psicologia comportamental e cognitiva: da reflexão teórica à diversidade na aplicação. (Vol. 4, pp. 164-171). Santo André: Esetec.

Berger, E., Morettin, A. V. \& Neto, L. B. (1991). Introdução à clínica do acompanhante terapêutico: história. Em Equipe de Acompanhantes Terapêuticos do Hospital-Dia A casa
(Org), A rua como espaço clínico (pp. 17-23). São Paulo: Escuta.

Brito, A. M. W. \& Dessen, M. A. (1999). Crianças surdas e suas famílias: um panorama geral. Psicologia Reflexão $e$ Critica, 12(2), 429-445. Disponível em: <http://www. scielo.br>. (Acesso em 02/11/2004).

Caballo, V. E. (1999, $3^{\text {a }}$ ed.). Manual de técnicas de terapia e modificação do comportamento. São Paulo: Santos Editora.

Guedes, M. L. (1993). Equívocos da Terapia Comportamental. Temas em Psicologia, 2, 81-85.

Ibrahim, C. (1991). Do louco à loucura: o percurso do auxiliar psiquiátrico no Rio de Janeiro. Em Equipe de acompanhantes terapêuticos do Hospital-Dia A Casa (Org.), A rua como espaço clínico. (pp.43-49). São Paulo: Escuta.

Laville, C. \& Dionne J. (1999). A construção do saber: manual de metodologia da pesquisa em ciências humanas. Porto Alegre: Artmed.

Matos, M. A. (1999). Análise funcional. Estudos de Psicologia, 16(3), 8-18.

Mauer, S. K. \& Resnizky, S. (1987). Acompanhantes terapêuticos e pacientes psicóticos: manual introdutório de uma estratégia clinica. (W. P. Rosa, Trad.). Campinas: Papirus.

Pinto, R. A., Borges, V., Aguiar, P., Ferraz, F., Hisatugo, M., \& Ferraz, H. B. (2002). Avaliação das atividades da vida diária dos pacientes com doença de Parkinson submetidos a cirurgia estereotáxica. Arquivos de Neuropsiquiatria, 60(2B), 435-441. Disponível em: <http://www.scielo.br> (Acesso em 02/11/2004).

Porto, M. \& Sereno, D. (1991). Sobre acompanhamento terapêutico. Em Equipe de Acompanhantes terapêuticos do Hospital-Dia A Casa, (Org), A rua como espaço clínico. (pp. 23-31). São Paulo: Escuta.

Rangé, B. (1998). Psicoterapia Comportamental. Em B. Rangé, (Org.), Psicoterapia comportamental e cognitiva: pesquisa, prática, aplicações e problemas. (pp. 44-55). Campinas: Editorial Psy.

Ribeiro, T. C. (2002). Acompanhar é uma barra: considerações teóricas e clínicas sobre o acompanhamento terapêutico. Psicologia: Ciência e Profissão, 22(2), 78-87.

Zamignani, D. R. \& Wielenska, R. C. (1999). Redefinindo o papel do acompanhante terapêutico. Em R. R. Kerbauy \& R. C. Wielenska (Orgs.), Sobre comportamento $e$ cognição: psicologia comportamental e cognitiva - da reflexão teórica à diversidade na aplicação. (Vol.4, pp. 156-163). Santo André: Esetec.

Recebido em 27/06/2005 Aceito em 29/05/2006

Endereço para correspondência: Igor Londero. Rua Canela, 155, CEP 91740-190, Porto Alegre-RS.

E-mail: igorlondero@ibestvip.com.br 